\title{
TRIGONOMETRIC SHEAR DEFORMATION THEORY FOR THICK SIMPLY SUPPORTED BEAMS
}

\author{
Sachin Salve ${ }^{1}$, Ajay G. Dahake ${ }^{2}$, Gajendra Gandhe ${ }^{3}$, Durgesh Tupe ${ }^{4}$, Rahul patil ${ }^{5}$ \\ ${ }^{1}$ Sachin B. Salve, ME (Structure Pursuing), DIEMS Aurangabad, ssalve47@gmail.com \\ ${ }^{2}$ Ajay G. Dahake, HOD at Civil Engineering Dept. MIT Aurangabad, ajaydahake@gmail.com \\ ${ }^{3}$ Gajendra R. Gandhe, HOD at Civil Engineering Dept.DIEMS, Aurangabad, gajendra_gandhe@yahoo.co.in \\ ${ }^{4}$ Durgesh Tupe, Assistant Professor at Civil Engineering Dept. DIEMS, Aurangabad,durgeshtupe@gmail.com \\ ${ }^{5}$ Rahul S. Patil, Assistant Professor at Civil Engineering Dept. DIEMS, Aurangabad, rahulspatil0286@gmail.com \\ Corresponding Author - Sachin B. Salve, ME (Structure Pursuing), DIEMS Aurangabad,
}

Email: ssalve47@gmail.com

Contact No: $+919579132838,+917385037933$

\begin{abstract}
A trigonometric shear deformation theory for flexure of thick beams, taking into account transverse shear deformation effects, is developed. The number of variables in the present theory is same as that in the first order shear deformation theory. The sinusoidal function is used in displacement field in terms of thickness coordinate to represent the shear deformation effects. The noteworthy feature of this theory is that the transverse shear stresses can be obtained directly from the use of constitutive relations with excellent accuracy, satisfying the shear stress free conditions on the top and bottom surfaces of the beam. Hence, the theory obviates the need of shear correction factor. Governing differential equations and boundary conditions are obtained by using the principle of virtual work. The thick isotropic beams are considered for the numerical studies to demonstrate the efficiency of the theory. It has been shown that the theory is capable of predicting the local effect of stress concentration due to fixity of support. The fixed isotropic beams subjected to parabolic and cosine loads are examined using the present theory. Results obtained are discussed critically with those of other theories.
\end{abstract}

Keywords: Thick beam, trigonometric shear deformation, principle of virtual work, equilibrium equations, displacement, stress.

\section{INTRODUCTION}

It is well-known that elementary theory of bending of beam based on Euler-Bernoulli hypothesis disregards the effects of the shear deformation and stress concentration. The theory is suitable for slender beams and is not suitable for thick or deep beams since it is based on the assumption that the transverse normal to neutral axis remains so during bending and after bending, implying that the transverse shear strain is zero. Since theory neglects the transverse shear deformation, it underestimates deflections in case of thick beams where shear deformation effects are significant. Bresse [1], Rayleigh [2] and Timoshenko [3] were the pioneer investigators to include refined effects such as rotatory inertia and shear deformation in the beam theory. Timoshenko showed that the effect of transverse vibration of prismatic bars. This theory is now widely referred to as Timoshenko beam theory or first order shear deformation theory (FSDT) in the literature. In this theory transverse shear strain distribution is assumed to be constant through the beam thickness and thus requires shear correction factor to appropriately represent the strain energy of deformation. Cowper [4] has given refined expression for the shear correction factor for different cross-sections of beam. The accuracy of Timoshenko beam theory for transverse vibrations of simply supported beam in respect of the fundamental frequency is verified by Cowper [5] with a plane stress exact elasticity solution. To remove the discrepancies in classical and first order shear deformation theories, higher order or refined shear deformation theories were developed and are available in the open literature for static and vibration analysis of beam. Levinson [6], Bickford [7], Rehfield and Murty [8], Krishna Murty [9], Baluch, Azad and Khidir [10], Bhimaraddi and Chandrashekhara [11] presented parabolic shear deformation theories assuming a higher variation of axial displacement in terms of thickness coordinate. These theories satisfy shear stress free boundary conditions on top and bottom surfaces of beam and thus obviate the need of shear correction factor. Irretier [12] studied the refined dynamical effects in linear, homogenous beam according to theories, which exceed the limits of the Euler- Bernoulli beam theory. These effects are rotary inertia, shear deformation, rotary inertia and shear deformation, axial pre-stress, twist and coupling between bending and torsion. Kant and Gupta [13], Heyliger and Reddy [14] presented finite element models based on higher order shear deformation uniform rectangular beams. However, these displacement based finite element models are not free from phenomenon of shear locking (Averill and Reddy [15], Reddy [16]). There is another class of refined 
theories, which includes trigonometric functions to represent the shear deformation effects through the thickness. Vlasov and Leont'ev [17], Stein [18] developed refined shear deformation theories for thick beams including sinusoidal function in terms of thickness coordinate in displacement field. However, with these theories shear stress free boundary conditions are not satisfied at top and bottom surfaces of the beam. A study of literature by Ghugal and Shimpi [19] indicates that the research work dealing with flexural analysis of thick beams using refined trigonometric and hyperbolic shear deformation theories is very scarce and is still in infancy. In this paper development of theory and its application to thick simply supported beam is presented.

\section{DEVELOPMENT OF THEORY}

The beam under consideration as shown in Fig. 1 occupies in $0-x-y-z$ Cartesian coordinate system the region:

Where $x, y, z$ are Cartesian coordinates, $L$ and $b$ are the length and width of beam in the $\mathrm{x}$ and $y$ directions respectively, and $h$ is the thickness of the beam in the $\mathrm{z}$ direction. The beam is made up of homogeneous, linearly elastic isotropic material.

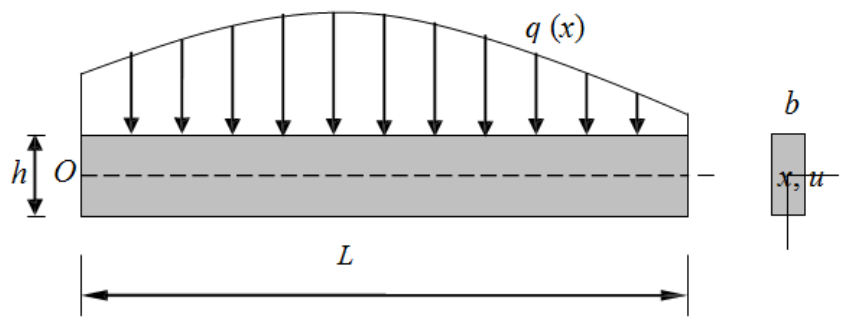

A. The displacement field

$$
\begin{aligned}
& u(x, z)=-z \frac{d w}{d x}+\frac{h}{\pi} \sin \frac{\pi z}{h} \phi(x) \\
& w(x, z)=w(x)
\end{aligned}
$$

Where the axial displacement in $\mathrm{x}$ direction and $\mathrm{w}$ is is the transverse displacement in $z$ direction of the beam. The sinusoidal function is assigned according to the shear stress distribution through the thickness of the beam. The function represents rotation of the beam at neutral axis, which is an unknown function to be determined. The normal and shear strains obtained within the framework of linear theory of elasticity using displacement field given by equation (1) are as follows.

Normal Strain

$$
\varepsilon_{x}=\frac{\partial u}{\partial x}=-z \frac{d^{2} w}{d x^{2}}+\frac{h}{\pi} \sin \frac{\pi z}{h} \frac{d \phi}{d x}
$$

Shear Strain

$$
\gamma_{z x}=\frac{\partial u}{\partial z}+\frac{d w}{d x}=\cos \frac{\pi z}{h} \phi
$$

The stress-strain relationships used are as follows:

$$
\begin{aligned}
& \sigma_{X}=E \varepsilon_{x}=-E z \frac{d^{2} w}{d x^{2}}+\frac{E h}{\pi} \sin \frac{\pi z}{h} \frac{d \phi}{d x} \\
& \tau_{z x}=G \gamma_{z x}=G \cos \frac{\pi z}{h} \phi
\end{aligned}
$$

\section{B. Governing Equations and Boundary Conditions}

-Using (2) through (4) and using the principle of virtual work, variationally consistent governing differential equations and boundary conditions for the beam under consideration can be obtained. The principle of virtual work when applied to the beam leads to:

$$
b \int_{x=0}^{x=L} \int_{z=-h / 2}^{z=+h / 2}\left(\sigma_{x} \delta \varepsilon_{x}+\tau_{z x} \delta \gamma_{z x}\right) d x d z-\int_{X=0}^{X=L} q(x) \delta w d x=0
$$

where the symboldenotes the variational operator. -Employing Green's theorem to (4) successivelyll, we obtain the coupled Euler-Lagrange equations which are the governing differential equations and associated boundary conditions of the beam. The governing differential equations obtained are as follows:

$$
\begin{aligned}
& E I \frac{d^{4} w}{d x^{4}}-\frac{24}{\pi^{3}} E I \frac{d^{3} \phi}{d x^{3}}=q(x) \\
& \frac{24}{\pi^{3}} E I \frac{d^{3} w}{d x^{3}}-\frac{6}{\pi^{2}} E I \frac{d^{2} \phi}{d x^{2}}+\frac{G A}{2} \phi=0
\end{aligned}
$$

The associated consistent natural boundary conditions obtained are of following form:

At the ends $x=0$ and $x=L$

$$
\begin{aligned}
& V_{x}=E I \frac{d^{3} w}{d x^{3}}-\frac{24}{\pi^{3}} E I \frac{d^{2} \phi}{d x^{2}}=0 \text { Or } w \text { is prescribed } \\
& M_{x}=E I \frac{d^{2} w}{d x^{2}}-\frac{24}{\pi^{3}} E I \frac{d \phi}{d x}=0 \text { Or } \frac{d w}{d x} \text { is prescribed } \\
& M_{s}=E I \frac{24}{\pi^{3}} \frac{d^{2} w}{d x^{2}}-\frac{6}{\pi^{2}} E I \frac{d \phi}{d x}=0 \text { Or } \phi \text { is prescribed }
\end{aligned}
$$

Thus the boundary value problem of the beam bending is given by the above variationally consistent governing differential equations and boundary conditions.

C. The General Solution of Governing Equilibrium Equations of the Beam 
The general solution for transverse displacement $w(x)$ and warping function( $x$ ) is obtained using (6) and (7) using method of solution of linear differential equations with constant coefficients. Integrating and rearranging (6) we obtain the following expression.

$\frac{d^{3} w}{d x^{3}}=\frac{24}{\pi^{3}} \frac{d^{2} \phi}{d x^{2}}+\frac{Q(x)}{E I}$

Where $Q(x)$ is the generalized shear force for beam and it is given by $Q(x)=\int^{x} q d x+C_{1}$

Now (7) is rearranged in the following form:

$$
\frac{d^{3} w}{d x^{3}}=\frac{\pi}{4} \frac{d^{2} \phi}{d x^{2}}-\beta \phi
$$

A single equation in terms of $\phi$ is now is obtained using (11) and (12) as

$$
\frac{d^{2} \phi}{d x^{2}}-\lambda^{2} \phi=\frac{Q(x)}{\alpha E I}
$$

Where the constants $\alpha, \beta$ and $\lambda$ appeared in Eqns. (12) and (13) are as follows

$$
\alpha=\left(\frac{\pi}{4}-\frac{24}{\pi^{3}}\right), \beta=\left(\frac{\pi^{3}}{48} \frac{G A}{E I}\right)
$$

$$
\lambda^{2}=\frac{\beta}{\alpha}
$$

The general solution of (13) is as follows:

$$
\phi(x)=C_{2} \cosh \lambda x+C_{3} \sinh \lambda x-\frac{Q(x)}{\beta E I}
$$

The equation of transverse displacement $w(x)$ is obtained by substituting the expression of in (12) and then integrating it thrice with respect to $x$. The general solution for $w(x)$ is obtained as follows

$$
\begin{aligned}
& E I w(x)=\iiint q d x d x d x d x+\frac{C_{1} x^{3}}{6}+\left(\frac{\pi}{4} \lambda^{2}-\beta\right) \frac{E I}{\lambda^{3}}\left(C_{2} \sinh \lambda x+C_{3} \cosh \lambda x\right) \\
& +C_{4} \frac{x^{2}}{2}+C_{5} x+C_{6}
\end{aligned}
$$

Where $C_{1}, C_{2}, C_{3}, C_{4}, C_{5}$ and $C_{6}$ are the arbitrary constants of integration and can be obtained by imposing natural (forced) and /or geometric or kinematical boundary / end conditions of beam.

\section{ILLUSTRATIVE EXAMPLES}

In order to prove the efficacy of the present theory, the following numerical examples are considered. The following material properties for beam are used

$E=210 \mathrm{GPa}, \mu=0.3$ and $=7800 \mathrm{~kg} / \mathrm{m} 3$, where $\mathrm{E}$ is the Young's modulus, is the density, and $\mu$ is the Poisson's Units

\section{A. Simply supported beam subjected to varying load,}

The simply supported beam is having its origin at left support and is simply supported at

$x=0$ and $x=L$. The beam is subjected to varying load, on surface $z=+h / 2$ acting in the downward $z$ direction with maximum intensity of load $q_{0}$.

$q(x)=q_{0} \frac{x}{L}$

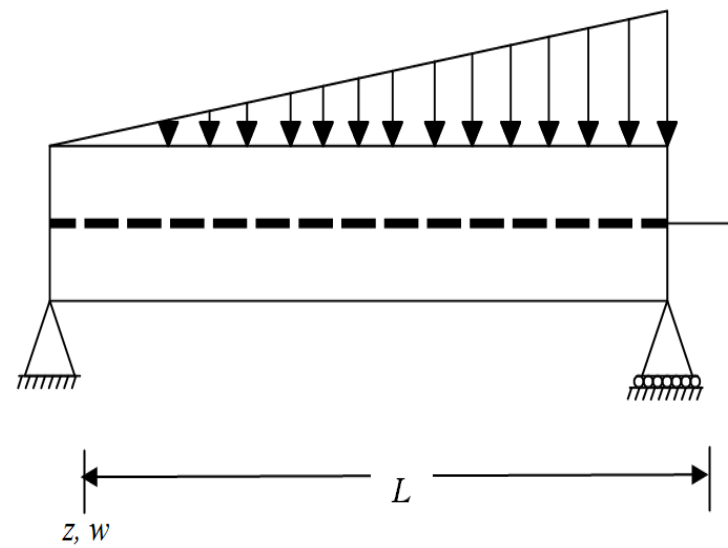

Figure 2: Simply supported beam with varying load

General expression obtained for $w(x)$ and $\phi(x)$ are as follows:

$$
\begin{aligned}
& w(x)=\frac{q_{0} L^{4}}{120 E I}\left[\frac{x^{5}}{L^{5}}-\frac{10}{3} \frac{x^{3}}{L^{3}}+\frac{7}{3} \frac{x}{L}-\frac{20}{\pi^{2}} \frac{E}{G} \frac{h^{2}}{L^{2}}\left(\frac{x^{3}}{L^{3}}-\frac{x}{L}+\frac{\sinh \lambda x-\cosh \lambda \mathrm{x}+1}{\lambda L}\right)\right] \\
& \phi(x)=\frac{q_{0} L}{\beta E I}\left(\frac{1}{6}-\frac{1}{2} \frac{x^{2}}{L^{2}}+\frac{\cosh \lambda x}{\lambda L \sinh \lambda L}\right)
\end{aligned}
$$

The axial displacement and stresses obtained based on above solutions are as follows

$$
u=\frac{q_{0} h}{E b}\left\{\begin{array}{l}
-\frac{1}{10} \frac{z}{h} \frac{L^{3}}{h^{3}}\left[5 \frac{x^{4}}{L^{4}}-10 \frac{x^{2}}{L^{2}}+\frac{7}{3}-\frac{20}{\pi^{2}} \frac{E}{G} \frac{h^{2}}{L^{2}}\left(3 \frac{x^{2}}{L^{2}}-1+\cosh \lambda x-\sinh \lambda x\right)\right] \\
+\frac{48}{\pi^{4}} \frac{E}{G} \sin \frac{\pi z}{h} \frac{L}{h}\left(-\frac{1}{2} \frac{x^{2}}{L^{2}}+\frac{1}{6}\right)
\end{array}\right\}
$$

$\sigma_{x}=\frac{q_{0}}{b}\left\{-\frac{1}{10} \frac{z}{h} \frac{L^{2}}{h^{2}}\left(20 \frac{x^{3}}{L^{3}}-20 \frac{x}{L}-\frac{120}{\pi^{2}} \frac{E}{G} \frac{h^{2}}{L^{2}} \frac{x}{L}\right)-\frac{48}{\pi^{4}} \frac{E}{G} \sin \frac{\pi z}{h} \frac{x}{L}\right\}$

$$
\tau_{z x}^{C R}=\frac{48}{\pi^{3}} \frac{q_{0}}{b} \frac{L}{h} \cos \frac{\pi z}{h}\left(\frac{1}{2} \frac{x^{2}}{L^{2}}-\frac{1}{6}-\frac{\cosh \lambda x}{\lambda L \sinh \lambda L}\right)
$$


$\tau_{z x}^{E E}=\frac{q_{0} L}{80 b h}\left(4 \frac{z^{2}}{h^{2}}-1\right)\left[60 \frac{x^{2}}{L^{2}}-20-\frac{120}{\pi^{2}} \frac{E}{G} \frac{h^{2}}{L^{2}}\right]+\frac{48}{\pi^{5}} \cos \frac{\pi z}{h} \frac{E}{G} \frac{q_{0} h}{b L}$

\section{RESULTS}

In this paper, the results for inplane displacement, transverse displacement, inplane and transverse stresses are presented in the following non dimensional form for the purpose of presenting the results in this work.

For beams subjected to parabolic load, $q(x)$

$\bar{u}=\frac{E b u}{q_{0} h}, \overline{\mathrm{w}}=\frac{10 E b h^{3}}{q_{0} L^{4}}, \bar{\sigma}_{x}=\frac{b \sigma_{x}}{q_{0}}, \bar{\tau}_{z x}=\frac{b \tau_{z x}}{q_{0}}$

Table I: Non-Dimensional Axial Displacement $\bar{u}$ at $(x=$ $0.75 L, z=h / 2)$, Transverse Deflection $(\bar{w})$ at $(x=0.75 L, z$ $=0.0)$ Axial Stress $\left(\bar{\sigma}_{x}\right)$ at $(x=0.75 L, z=h / 2)$ Maximum Transverse Shear Stresses $\left(\bar{\tau}_{z x} C R\right)$ and $\left(\bar{\tau}_{z x} E E\right)(x=0, z$ $=0.0$ ) of the Simply Supported Beam Subjected to Varying Load for Aspect Ratio 4.

\begin{tabular}{|l|c|c|c|c|c|}
\hline Model & $\bar{u}$ & $(\bar{w})$ & $\left(\bar{\sigma}_{x}\right)$ & $\left(\bar{\tau}_{z x} C R\right)$ & $\left(\bar{\tau}_{z x} E E\right)$ \\
\hline TSDT & $\begin{array}{c}- \\
5.6081\end{array}$ & 0.6897 & $\begin{array}{c}- \\
5.4746\end{array}$ & -1.0320 & 0.9968 \\
\hline FSDT & $\begin{array}{c}- \\
5.4708\end{array}$ & 0.6877 & $\begin{array}{c}- \\
5.2500\end{array}$ & 0.1436 & 1.0000 \\
\hline ETB & $\begin{array}{c}- \\
5.4708\end{array}$ & 0.5811 & $\begin{array}{c}- \\
5.2500\end{array}$ & --- & 1.0000 \\
\hline
\end{tabular}

Table II: Non-Dimensional Axial Displacement $\bar{u}$ at $(x$ $=0.75 L, z=h / 2)$, Transverse Deflection $(\bar{w})$ at $(x=$ $0.75 L, z=0.0)$ Axial Stress $\left(\bar{\sigma}_{x}\right)$ at $(x=0.75 L, z=h / 2)$ Maximum Transverse Shear Stresses $\left(\bar{\tau}_{z x} C R\right)$ and $\left(\bar{\tau}_{z x} E E\right)(x=0, z=0.0)$ of the Simply Supported Beam Subjected to Varying Load for Aspect Ratio 10.

\begin{tabular}{|l|c|c|c|c|c|}
\hline $\begin{array}{l}\text { Mode } \\
1\end{array}$ & $\bar{u}$ & $(\bar{w})$ & $\left(\bar{\sigma}_{x}\right)$ & $\left(\bar{\tau}_{z x} C R\right)$ & $\left(\bar{\tau}_{z x} E E\right)$ \\
\hline TSDT & - & 0.598 & - & -2.5801 & 2.4987 \\
& 86.705 & 9 & 33.037 & & \\
& 7 & & 1 & & \\
\hline FSDT & - & 0.598 & - & -0.8974 & 2.5000 \\
& 85.481 & 1 & 32.812 & & \\
& 8 & & 5 & & \\
\hline ETB & - & 0.581 & - & --- & 2.5000 \\
& 85.481 & 1 & 32.812 & & \\
& 8 & & 5 & & \\
\hline
\end{tabular}

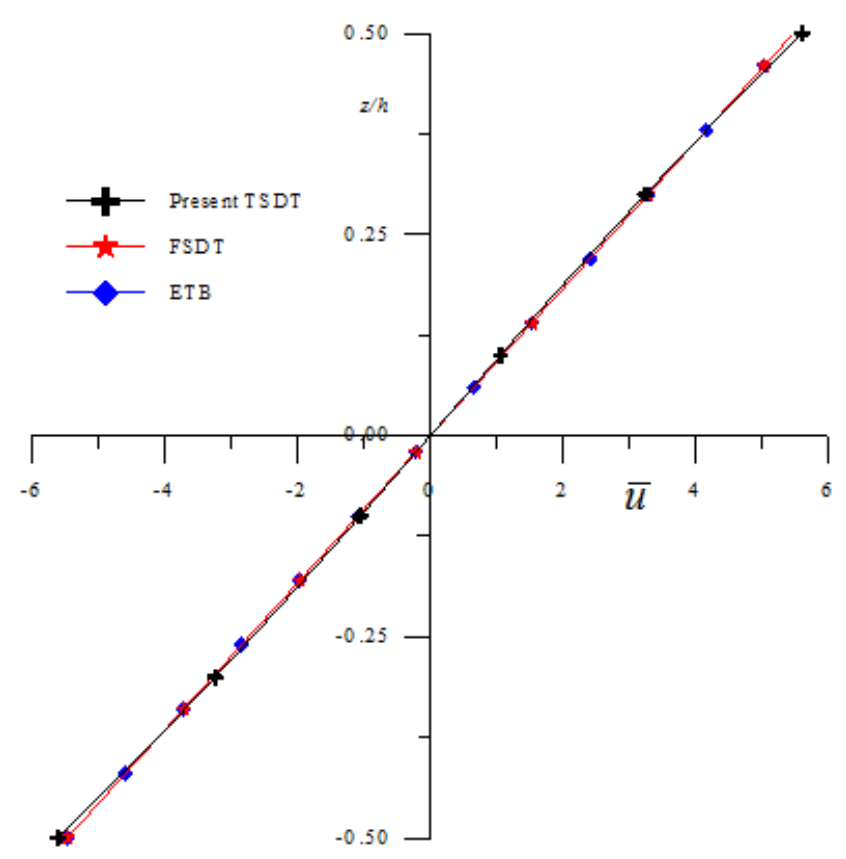

Fig 3: Variation of axial displacement $(\bar{u})$ through the thickness of simply supported beam at $(x=0.75 \mathrm{~L}, z)$ when subjected to varying load for aspect ratio 4. (Example 1)

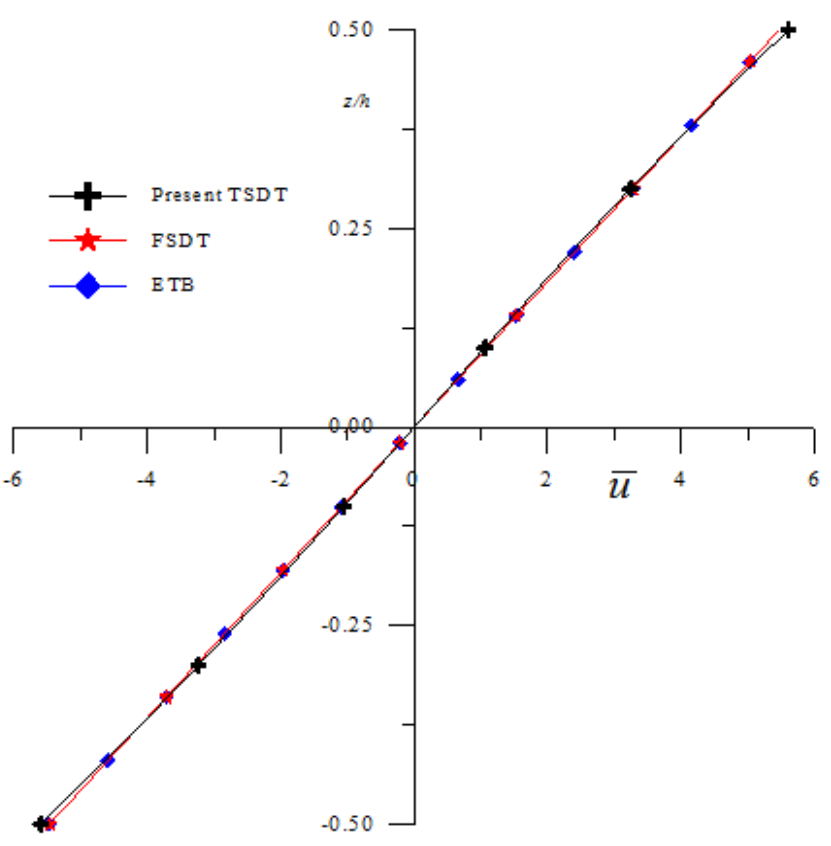

Fig 4: Variation of axial displacement $(\bar{u})$ through the thickness of simply supported beam at $(x=0.75 \mathrm{~L}, z)$ when subjected to varying load for aspect ratio 10. (Example 1) 


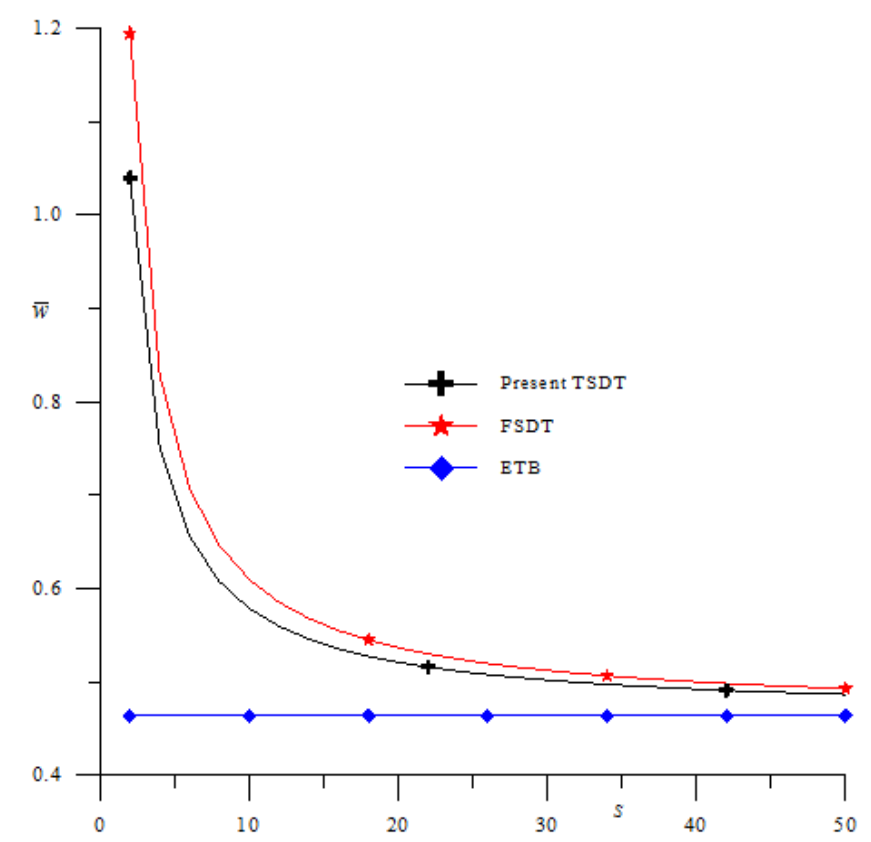

Fig. 5: Variation of maximum transverse displacement $(\bar{w})$ of simply supported beam at $(x=0.75 L, z=0)$ when subjected to varying load with aspect ratio $S$. (Example 1)

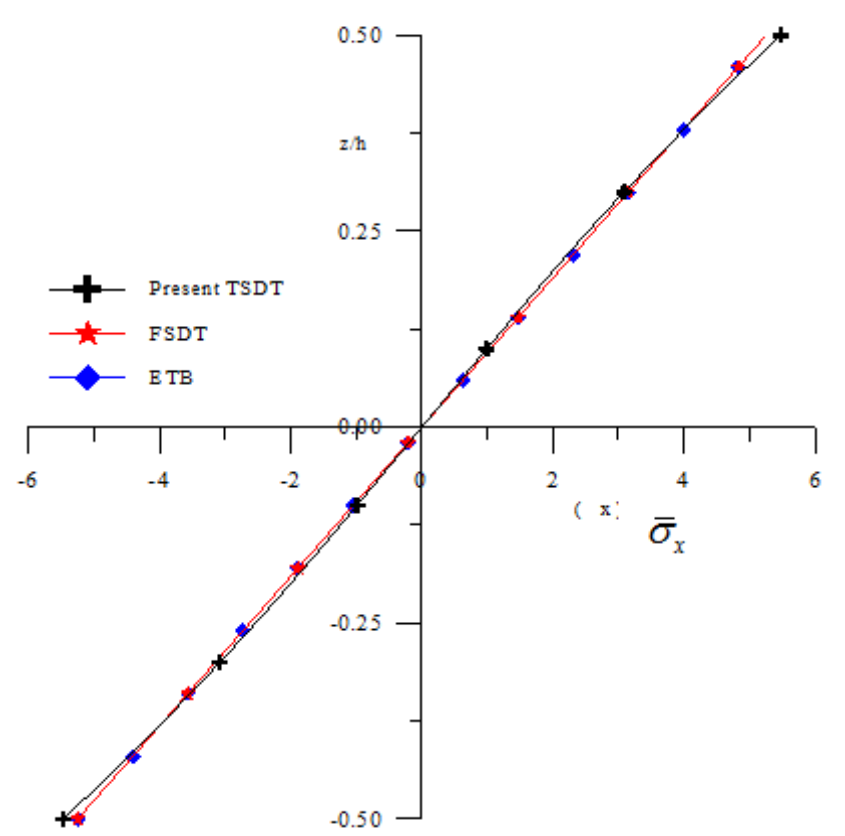

Fig. 6: Variation of axial stress $\left(\bar{\sigma}_{x}\right)$ through the thickness of simply supported beam at $(\mathrm{x}=0.75 \mathrm{~L}, z)$ when subjected to varying load for aspect ratio 4 . (Example 1)

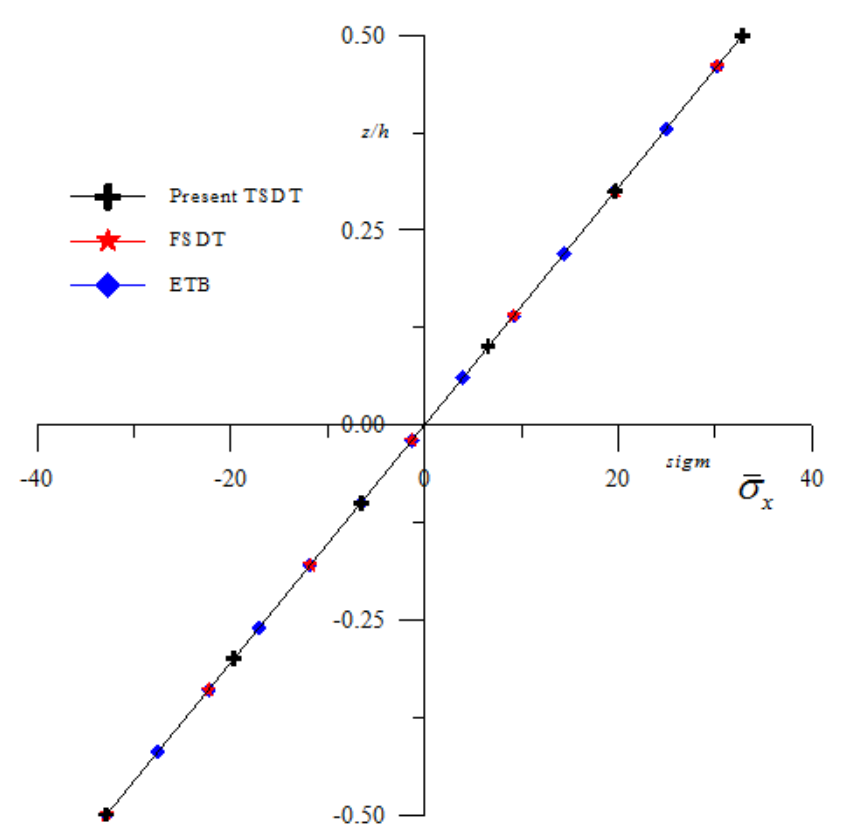

Fig. 7: Variation of axial stress $\left(\bar{\sigma}_{x}\right)$ of simply supported beam at $(\mathrm{x}=0.75 \mathrm{~L}, \mathrm{z})$ when subjected to parabolic load with aspect ratio 10. (Example 1)

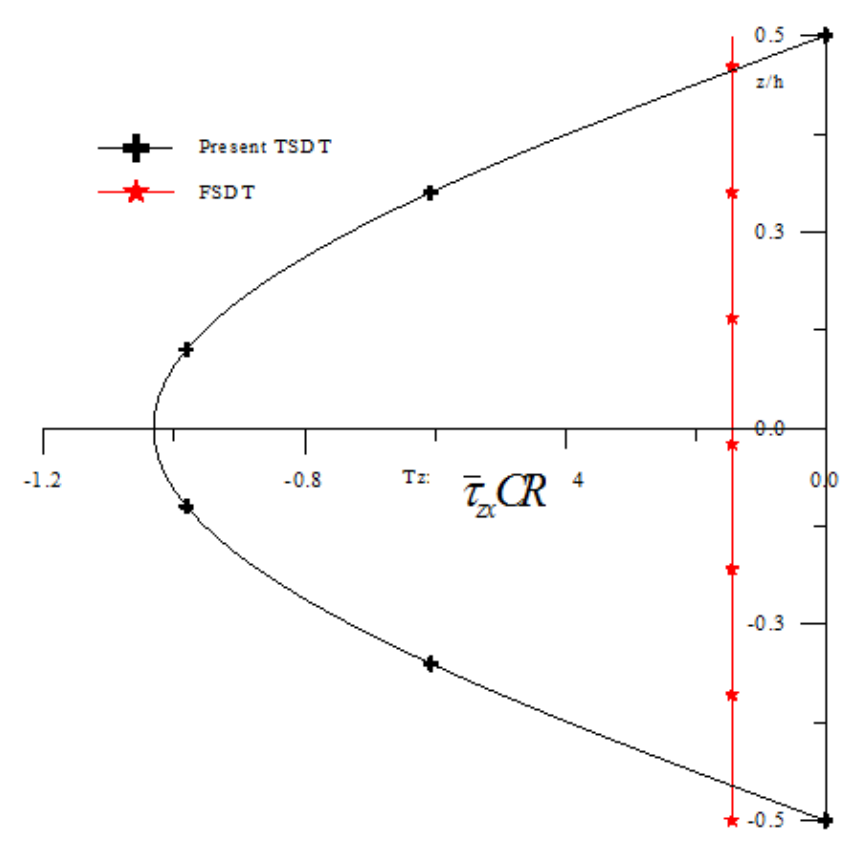

Fig. 8: Variation of transverse shear stress ( $\bar{\tau}_{z x} C R$ ) through the thickness of simply supported beam at $(\mathrm{x}=0$, $z$ ) when subjected to varying load and obtain using constitutive relation for aspect ratio 4. (Example 1) 


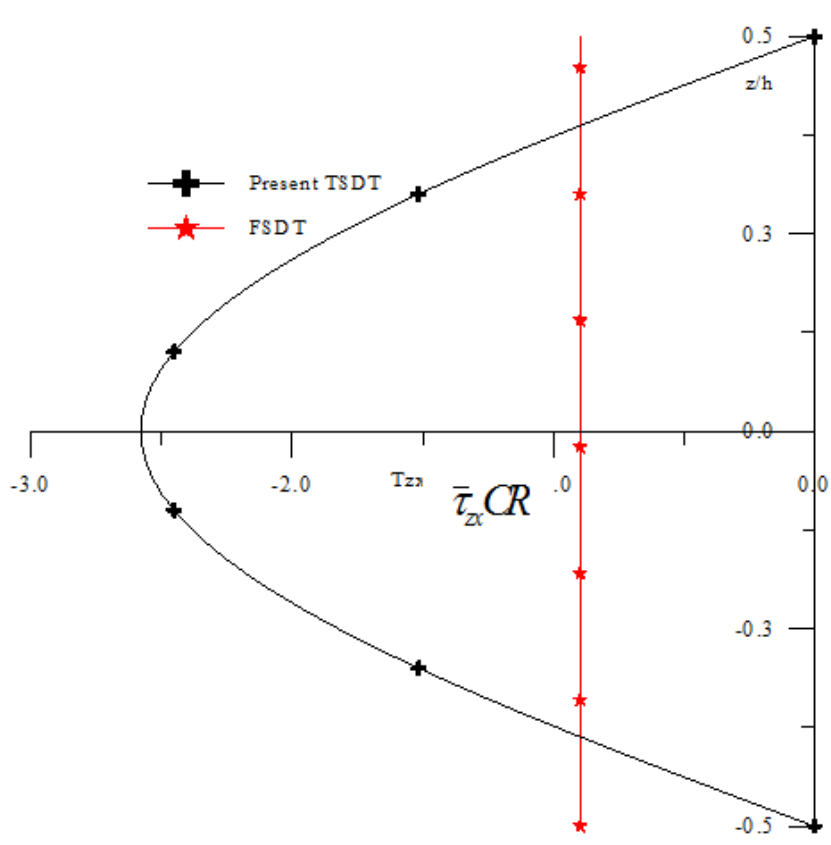

Fig. 9: Variation of transverse shear stress $\left(\bar{\tau}_{z x} C R\right)$ through the thickness of simply supported beam at $(\mathrm{x}=0$, $\mathrm{z}$ ) when subjected to varying load and obtain using constitutive relation for aspect ratio 10. (Example 1)

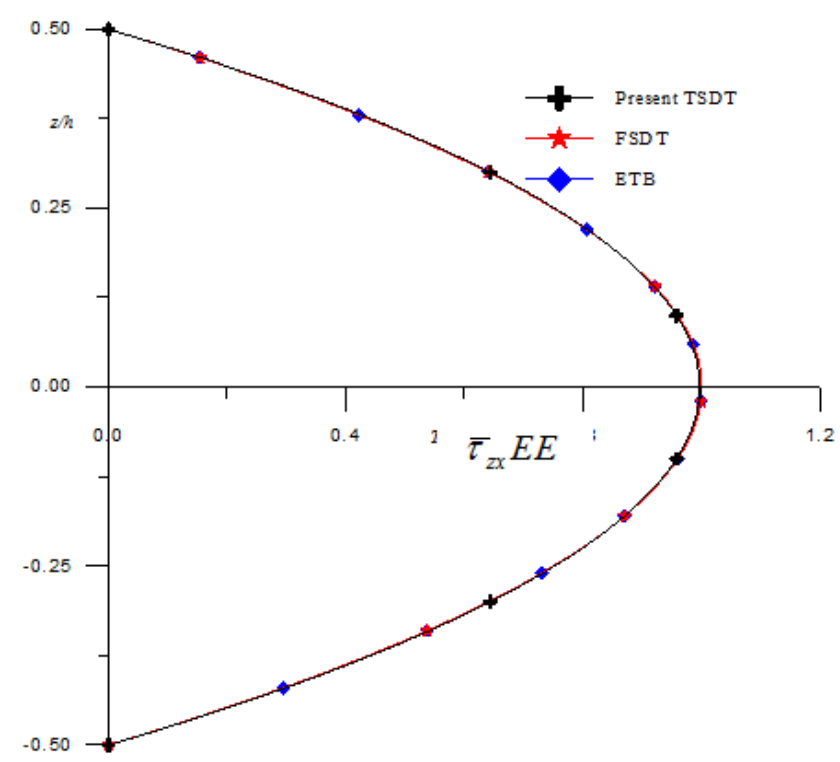

Fig. 10: Variation of transverse shear stress $\left(\bar{\tau}_{z x} E E\right)$ through the thickness of simply supported beam at $(\mathrm{x}=0$, z) when subjected to varying load and obtain using equilibrium equation for aspect ratio 4. (Example 1)

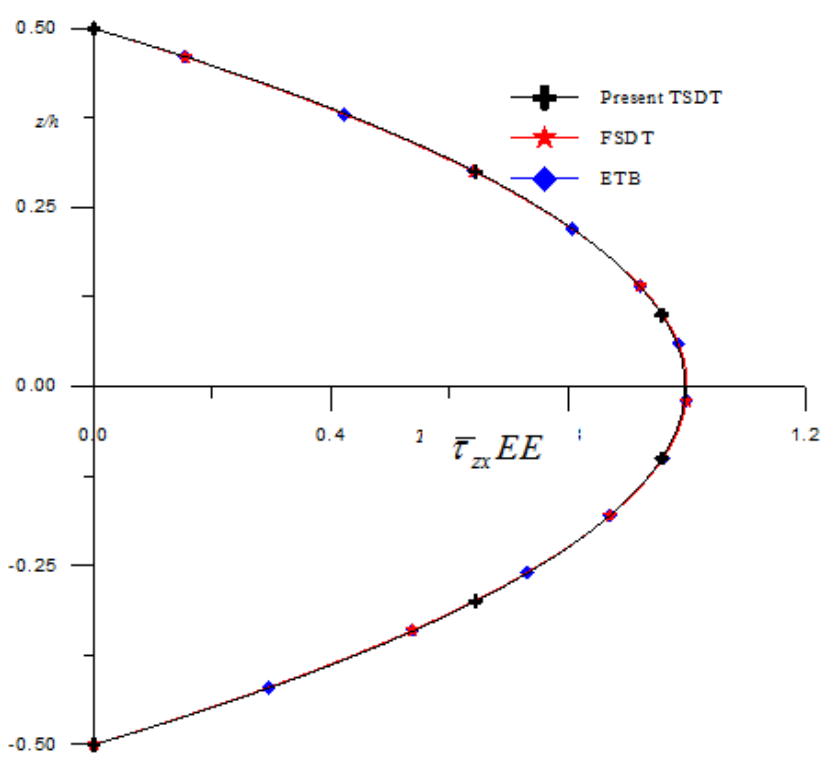

Fig. 11: Variation of transverse shear stress $\left(\bar{\tau}_{z x} E E\right)$ through the thickness of simply supported beam at $(\mathrm{x}=0, \mathrm{z})$ when subjected to varying load and obtain using equilibrium equation for aspect ratio 10. (Example 1)

\section{DISCUSSION OF RESULTS}

The comparison of results of maximum non-dimensional axial displacement $(\bar{u})$ for the aspect ratios of 4 and 10 is presented in Tables I and II for simply supported beams subjected to linearly varying and parabolic load (see Figure 2 ). The values of axial displacement given by present theory are in close agreement with the values of other refined theories for aspect ratio 4 and 10. The through thickness distribution of this displacement obtained by present theory is in close agreement with other refined theories as shown in Figures 3 and 5 for aspect ratio 4 and 10 .

The comparison of result of maximum non-dimensional transverse displacement $(\bar{w})$ for aspect ratio 4 and 10 is presented in Table I and II for simply supported beams subjected to linearly varying load. The value of present theory are in excellent agreement with the values of other refined theories for aspect ratio 4 and 10 except those of classical beam theory (ETB) and (FSDT) of Timoshenko. The variation of $(\bar{w})$ with aspect ratio $(S)$ is shown in Figure 4. The refined theories converge to the value of classical beam theory for higher aspect ratios.

The results of axial stress $\left(\bar{\sigma}_{x}\right)$ are shown in Tables I and II for aspect ratios 4 and 10. The axial stresses given by present theory are compared with other higher order shear deformation theories. It is observed that the results by present theory are in excellent agreement with other refined theories as well as ETB and FSDT. The through the thickness variation of this stress given by all the theories is linear at $x=0.75 \mathrm{~L}$. The variations of this stress are shown in Figures 6 and 7 .

The comparison of maximum non-dimensional transverse shear stress for simple beams with varying load obtained by 
the present theory and other refined theories is presented in Tables I and II for aspect ratio of 4 and 10 respectively. The maximum transverse shear stress obtained by present theory using constitutive relation is in good agreement with that of higher order theories for aspect ratio 4 and for aspect ratio 10. The through thickness variation of this stress obtained via constitutive relation are presented graphically in Figures 8 and 9 and those obtained via equilibrium equation are presented in Figures 10 and 11. The through thickness variation of this stress when obtained by various theories via equilibrium equation shows the excellent agreement with each other. The maximum value of this stress occurs at the neutral axis.

\section{CONCLUSION}

The variationally consistent theoretical formulation of the theory with general solution technique of governing differential equations is presented. The general solutions for beam with varying load are obtained in case of thick simply supported beam. The displacements and stresses obtained by present theory are in excellent agreement with those of other equivalent refined and higher order theories. The present theory yields the realistic variation of axial displacement and stresses through the thickness of beam. Thus the validity of the present theory is established.

\section{REFERENCES}

[1] J. A. C. Bresse, -Cours de Mechanique Appliquell, Mallet- Bachelier, Paris, 1859.

[2] J. W. S. Lord Rayleigh, - The Theory of Soundl, Macmillan Publishers, London, 1877.

[3] S. P. Timoshenko, J. N. Goodier, -Theory of Elasticityll, Third International Edition, McGraw-Hill, Singapore. 1970.

[4] G. R. Cowper, - The shear coefficients in Timoshenko beam theoryll, ASME Journal of Applied Mechanic, vol. 33, no. 2, 1966, pp. 335-340.

[5] G. R. Cowper, -On the accuracy of Timoshenko beam theoryll, ASCE J. of Engineering Mechanics Division. vol. 94, no. EM6, 1968, pp. 1447-1453,

[6] M. Levinson, - A new rectangular beam theoryll, Journal of Sound and Vibration, Vol. 74, No.1, 1981, pp. 81-87.

[7] W. B. Bickford, -A consistent higher order beam theoryll, International Proceeding of Development in Theoretical and Applied Mechanics (SECTAM), vol. 11, 1982, pp. 137-150,

[8] L. W. Rehfield, P. L. N. Murthy, -Toward a new engineering theory of bending: fundamentals\|, AIAA Journal, vol. 20, no. 5, 1982, pp. 693-699.

[9] A. V. Krishna Murty, -Towards a consistent beam theoryll, AIAA Journal, vol. 22, no. 6, 1984, pp. 811-816.

[10] M. H. Baluch, A. K. Azad, and M. A. Khidir, - Technical theory of beams with normal strainll, ASCE Journal of Engineering Mechanics, vol. 110, no. 8, 1984, pp. 1233- 1237.

[11] A. Bhimaraddi, K. Chandrashekhara, -Observations on higher order beam Theoryll, ASCE Journal of Aerospace Engineering, vol. 6, no. 4, 1993, pp. 408-413,
[12] H. Irretier, - Refined effects in beam theories and their influence on natural frequencies of beamll, International Proceeding of Euromech Colloquium, 219, on Refined Dynamical Theories of Beam, Plates and Shells and Their Applications, Edited by I. Elishak off and H. Irretier, Springer-Verlag, Berlin, 1986, pp. 163-179.

[13] T. Kant, A. Gupta, -A finite element model for higher order shears deformable beam theory", Journal of Sound and Vibration, vol. 125, no. 2, 1988, pp. 193-202.

[14] P. R. Heyliger, J.N. Reddy, -A higher order beam finite element for bending and vibration problemsl, Journal of Sound and Vibration, vol. 126, no. 2, 1988. pp. 309-326.

[15] R. C. Averill, J. N. Reddy, -An assessment of fournoded plate finite elements based on a generalized third order theoryll, International Journal of Numerical Methods in Engineering, vol. 33, 1992, pp. 1553-1572.

[16] J. N. Reddy, -An Introduction to Finite Element Method\|l. 2nd Ed., McGraw-Hill, Inc., New York, 1993.

[17] V. Z. Vlasov, U. N. Leont'ev, -Beams, Plates and Shells on Elastic Foundations\| Moskva, Chapter 1, 1-8. Translated from the Russian by A. Barouch and T. Plez Israel Program for Scientific Translation Ltd., Jerusalem, 1966.

[18] M. Stein, - Vibration of beams and plate strips with three dimensional flexibilityll, ASME J. of Applied Mechanics, vol. 56, no. 1, 1989, pp. 228-231.

[19] Y. M. Ghugal, R. P. Shmipi, -A review of refined shear deformation theories for isotropic and anisotropic laminated beamsll, Journal of Reinforced Plastics and Composites, vol. 20, no. 3, , 2001, pp. 255-272.

[20] Y. M. Ghugal, R. Sharma, -A hyperbolic shear deformation theory for flexure and vibration of thick isotropic beams\|, International Journal of Computational Methods, vol. 6, no. 4, 2009, pp. 585-604.

[21] F. B. Hildebrand, E. C. Reissner, -Distribution of Stress in Built-In Beam of Narrow Rectangular Cross Sectionl, Journal of Applied Mechanics, vol. 64, 1942, pp. 109-116.

[22] S.P. Timoshenko, - On the correction for shear of the differential equation for transverse vibrations of prismatic bars\|, Philosophical Magazine, vol. 41, no. 6, 1921, pp. 742746. 


\section{APPENDIX}

$\begin{array}{ll}A & \text { Cross sectional area of beam }=b h b \\ E, G, \mu & \text { Elastic constants of the material } \\ E & \text { Young's modulus } \\ G & \text { Shear modulus } \\ h & \text { Thickness of beam } \\ I & \text { Moment of inertia of beam } \\ K & \text { Shear correction factor } \\ L & \text { Span of the beam } \\ q & \text { Intensity of uniformly distributed transverse load } \\ S & \text { Aspect ratio for beam }=L / h \\ w & \text { Transverse displacement in z direction } \\ w & \text { Non-dimensional transverse displacement } \\ x, y, z & \text { Rectangular Cartesian coordinates } \\ \mu & \text { Possion's ratio of the beam material } \\ \rho & \text { Density of beam material } \\ \sigma x & \\ \sigma x & \quad \text { Non-dimensional transverse shear stress via equilibrium equation } \\ \tau z x & \quad \text { The deflection according to classical beam theory } \\ \left(\bar{\tau}_{z x} C R\right) & \text { Transverse shear stress via constitutive relations } \\ \left(\bar{\tau}_{z x} C R\right) & \text { Non-dimensional transverse shear stress via constitutive relations } \\ \left(\bar{\tau}_{z x} E E\right) & \quad \text { Transverse shear stress via equilibrium equations } \\ \left(\bar{\tau}_{z x} E E\right) & \quad \text { Nown functions associated with the shear slopes } \\ \phi x & \\ W_{B} & \end{array}$

Axial stress in $x$ directions

Non-dimensional axial stress in $x$ directions

Transverse shear stress in $z x$ plane

List of abbreviations ETB

CR

EE

TSDT

HPSDT

HSDT

FSDT
Elementary Theory of Beam

Constitutive Relations

Equilibrium Equations

Trigonometric Shear Deformation Theory

Hyperbolic Shear Deformation Theory

Third Order Shear Deformation Theory

First Order Shear Deformation Theory 